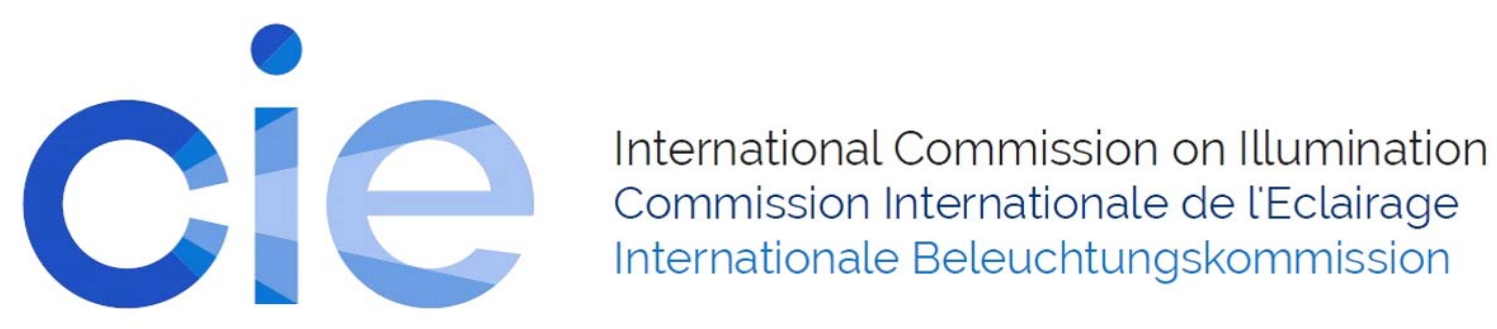

\title{
OP17
}

\section{STANDARD LEDS WITH SUPERIOR LONG-TERM STABILITY}

\author{
Yuqin Zong et al.
}

DOI 10.25039/x46.2019.OP17

from

CIE x046:2019

\author{
Proceedings \\ of the \\ 29th CIE SESSION \\ Washington D.C., USA, June 14 - 22, 2019 \\ (DOI 10.25039/x46.2019)
}

The paper has been presented at the 29th CIE Session, Washington D.C., USA, June 14-22, 2019. It has not been peer-reviewed by CIE.

\section{(C) CIE 2019}

All rights reserved. Unless otherwise specified, no part of this publication may be reproduced or utilized in any form or by any means, electronic or mechanical, including photocopying and microfilm, without permission in writing from CIE Central Bureau at the address below. Any mention of organizations or products does not imply endorsement by the CIE.

This paper is made available open access for individual use. However, in all other cases all rights are reserved unless explicit permission is sought from and given by the CIE.

CIE Central Bureau

Babenbergerstrasse 9

A-1010 Vienna

Austria

Tel.: +43 17143187

e-mail: ciecb@cie.co.at

www.cie.co.at 


\title{
STANDARD LEDS WITH SUPERIOR LONG-TERM STABILITY
}

\author{
Yuqin Zong ${ }^{1}$, Weiqiang Zhao' ${ }^{2}$ C. Cameron Miller ${ }^{1}$ \\ ${ }^{1}$ National Institute of Standards and Technology (NIST), Gaithersburg, Maryland, USA \\ ${ }^{2}$ Guest researcher at NIST from National Institute of Metrology (NIM), Beijing, CHINA
}

yuqin.zong@nist.gov

DOI $10.25039 / \times 46.2019 .0 P 17$

\begin{abstract}
A large-chip standard LED with superior long-term stability have been developed at NIST. The standard LED uses a large, specialty die rated for $50 \mathrm{~W}$ but is operated under $3 \mathrm{~W}$ to eliminate aging effect. The standard LED was seasoned for one year and measured for its long-term stability for three years. The measurement result shows that the long-term stability is on the level of $0.1 \%$ in the three-year time. The LED can be used as a transfer standard for luminous intensity, luminance, and total luminous flux.
\end{abstract}

Keywords: Standard LED, Long-term Stability, Photometry.

\section{Introduction}

Conventional incandescent standard lamps for detector and instrument calibrations (e.g., CIE Standard Illuminant A lamps used for photometer calibrations) are mostly discontinued by the manufacturers due to the revolution of the lighting technology in recent years. To address this issue and also to take advantages of the new solid-state lighting technology, the International Commission on Illumination (CIE) established a new technical committee TC 2-90 recently for developing new reference spectrum based on white LEDs for photometer calibrations. In addition, standard LEDs are being developed by LED manufacturers, national metrology labs, and instrument manufacturers. Most of these standard LEDs use a typical LED package design. They are temperature-controlled and have good short stabilities (days). However, on-shelf longterm stability of the existing standard LEDs is not well known and is typically not specified by the manufacturers, which limits their uses only as short-term working standards.

\section{The new standard LEDs}

We developed a standard LED using a large, specialty die for improving long-term stability. A schematic of the LED package is shown in Figure 1. The large die is a $3 \mathrm{~mm} \times 3 \mathrm{~mm}$ square monolithic device and is rated for $13.5 \mathrm{~A}, 50 \mathrm{~W}$ continuous operation. The die is packaged into a protection housing with a glass window to keep it clean and dry (the same form factor as that of a photodiode). The LED package is mounted on a star shape metal core printed circuit board (MCPCB). The light-emitting surface of the die is flat and coated with a thin layer of phosphor (with no encapsulation). The LED package has a uniform luminance distribution and a near Lambertion beam pattern. These characteristics make it a good luminous intensity transfer standard and a luminance transfer standard in addition to a good total luminous flux transfer standard. This type of LEDs is often used for applications such as high-power back light of an LCD projector, high-power fiber-coupled illumination, etc. The luminous efficacy of this type of specialty LEDs is low compared to a typical white LED, which is not an issue to be used as a standard LED.

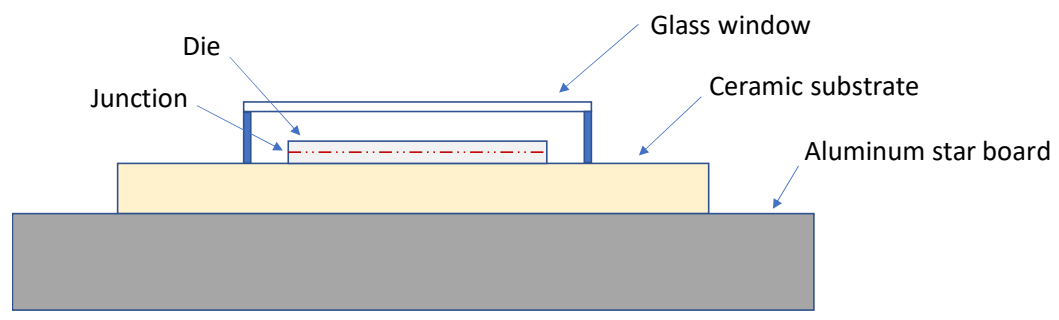

Figure 1 - Illustration of the LED package 
The LED package is mounted on the cold plate of a compact $(50.8 \mathrm{~mm} \times 50.8 \mathrm{~mm} \times 58 \mathrm{~mm})$ temperature-controlled mount (TCM). A $0.2 \mathrm{~mm}$ thick graphite-based thermal interfacing sheet is used between the star board and the cold plate to minimize the thermal resistance between the junction and the cold plate. The TCM has two connectors for operating the LED package; one for a current source and the other for a temperature controller. The housing of the TCM is clear anodized for reducing self-absorption when it is used in an integrating sphere. The LED's thermal resistance from the junction to the TCM cold plate is low (approximately $1{ }^{\circ} \mathrm{C} / \mathrm{W}$ as opposed to more than $10{ }^{\circ} \mathrm{C} / \mathrm{W}$ for a typical LED package) and the TCM is set to operate at the room temperature $\left(25^{\circ} \mathrm{C}\right)$, which minimizes the influence from ambient air temperature and air movement. Further, the $50 \mathrm{~W}$ LED package is operated only at $3 \mathrm{~W}$ level, which virtually eliminates its aging effect. A photograph of a standard LED including a LED package and a TCM is shown in Figure 2.

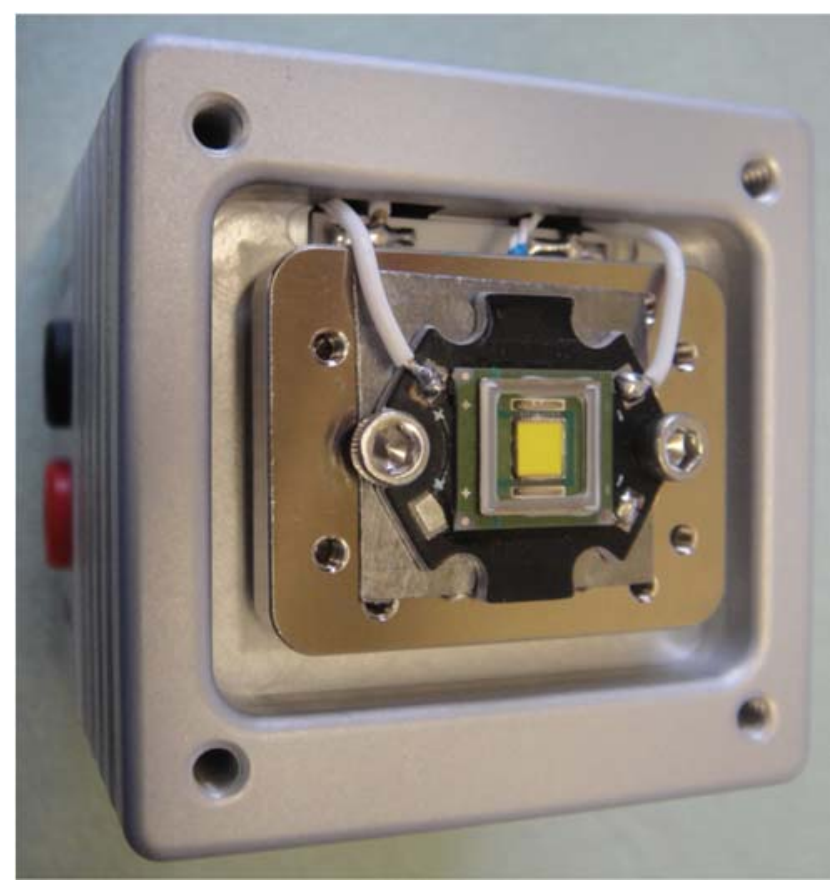

Figure 2 - Photograph of a standard LED

The LED is operated using a compact current source and temperature controller combo unit. It has a useful LED protection feature so that if its temperature controller is turned off accidently the current source will be automatically turned off immediately.

\section{Stability of the standard LED}

The standard LED was first evaluated for repeatability. A highly stable, temperature-controlled photometer was set up for measuring an standard LED at a distance of $400 \mathrm{~mm}$ for luminous intensity. The standard LED was operated at $1 \mathrm{~A}$ with its TCM temperature controlled at $25^{\circ} \mathrm{C}$. It was measured 10 times for luminous intensity. Between two consecutive measurements, the LED was turned off for at least one hour. Figure 3 shows the repeatability of the LED, which is better than $0.01 \%$ after it is stabilized for one hour. 


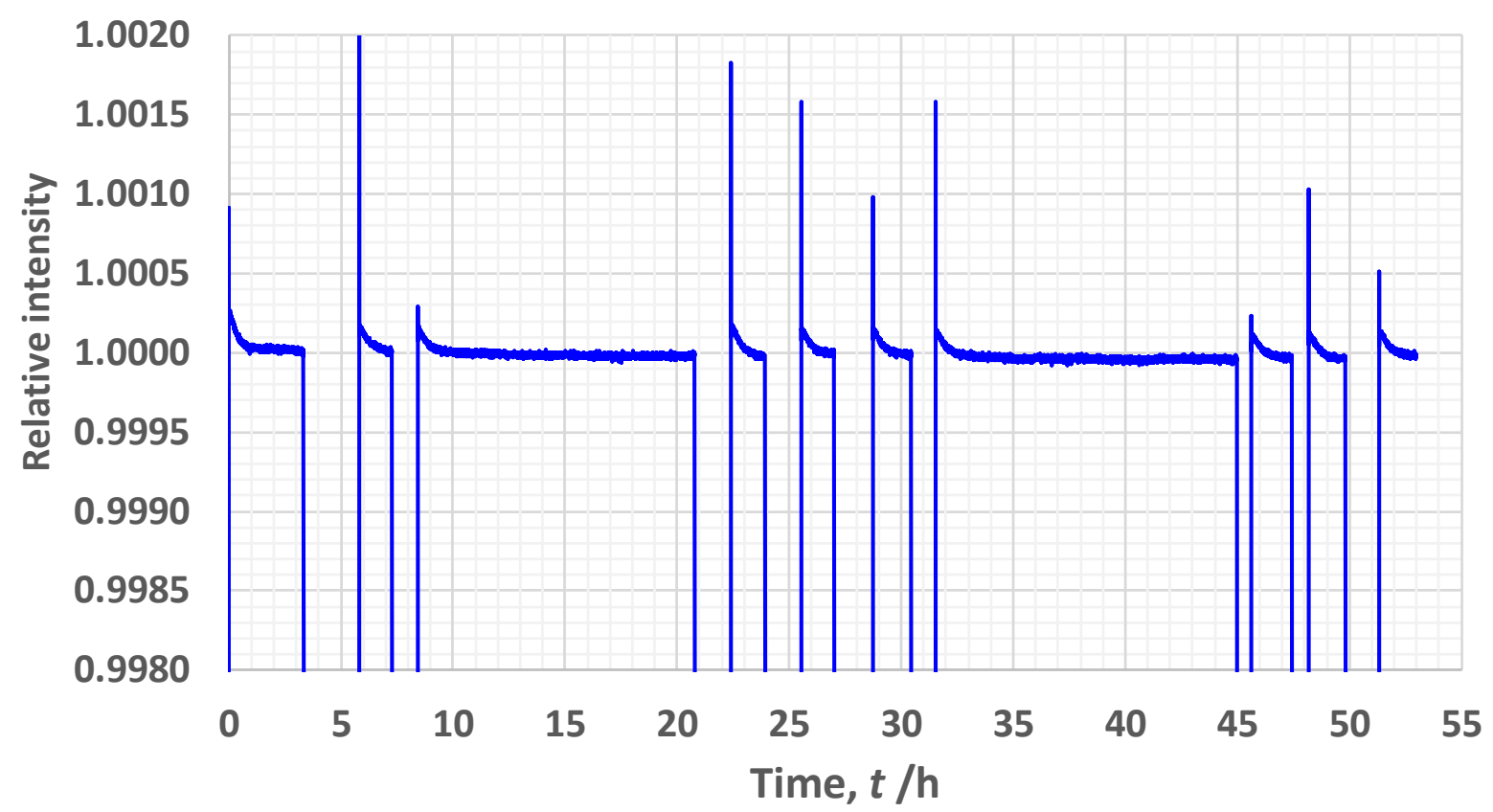

Figure 3 - Repeatability of a standard LED

The same standard LED, operating condition, and setup were also used for measuring aging rate. The standard LED was turned on and its intensity was measured every hour during most of the test time. Figure 4 shows the measurement results of the aging rate together with the room temperature for a period of more than 100 days. There is a $0.05 \%$ initial change during the first 10 days and then no change associated with aging. During Day 96 to Day 98 the room temperature rises from $24{ }^{\circ} \mathrm{C}$ to $29^{\circ} \mathrm{C}$, which results in a rise of luminous intensity for $0.04 \%$. This small increase of luminous intensity may be caused by a small change of temperature of the TCM's cold plate, even though the reading of the TCM cold plate temperature does not change. Note the thermistor inside the cold plate is not thermally insulated perfectly from the ambient air and therefore it may be affected by ambient air temperature.

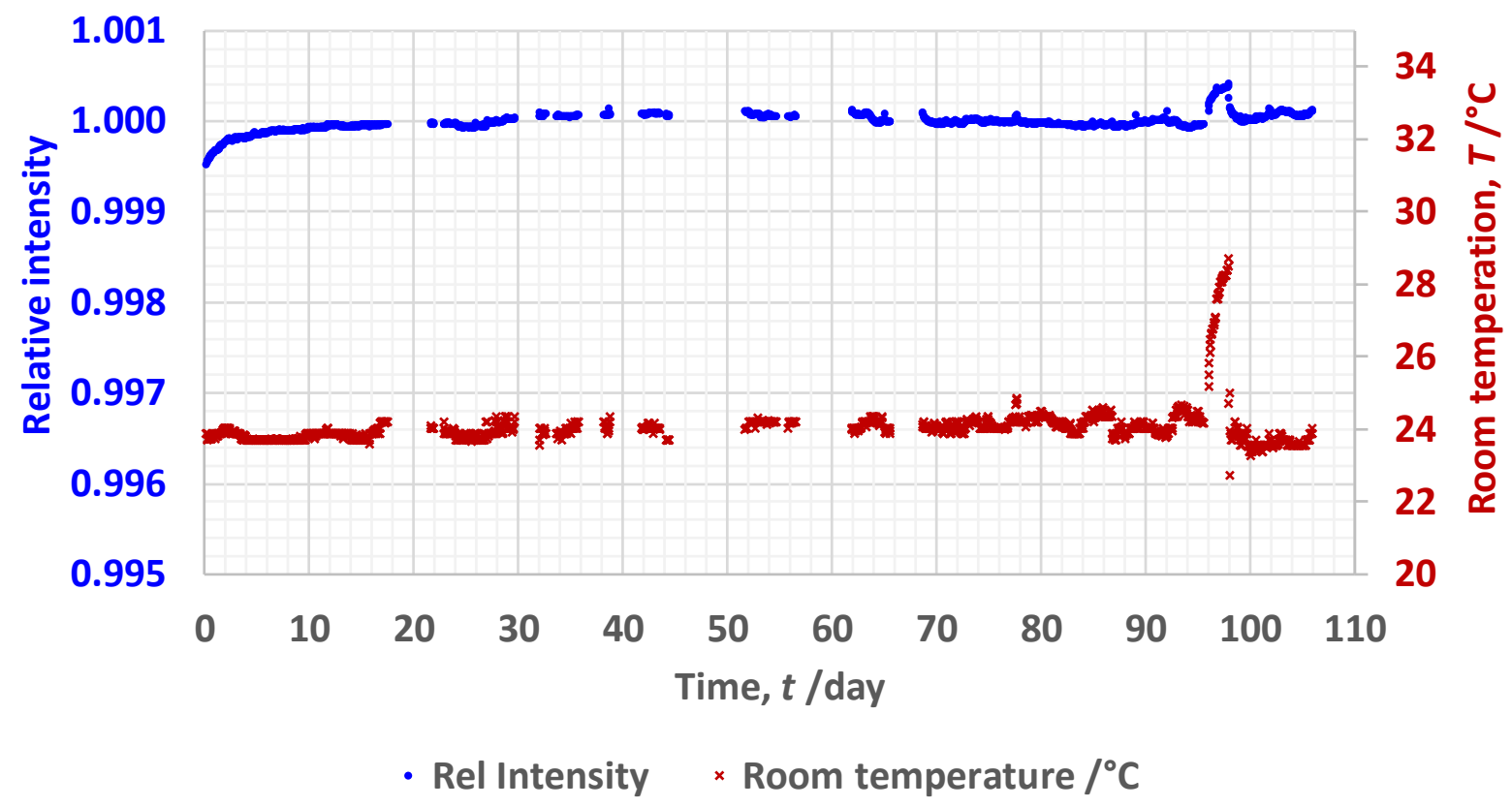

Figure 4 - Plot of aging rate 
Long-term stabilities of total luminous flux of 10 standard LEDs with designations of L\#21 to $\mathrm{L \# 30}$ were measured at $25{ }^{\circ} \mathrm{C} \mathrm{TCM}$ temperature and $1 \mathrm{~A}$ operating current for a period of approximately three years using the NIST $2.5 \mathrm{~m}$ absolute integrating sphere (NIST 2018). The first measurement time is when the 10 LED packages were brand new. After the first measurement, all standard LEDs were left on with $1 \mathrm{~A}$ operating current and $25{ }^{\circ} \mathrm{C}$ TCM temperature (for seasoning for approximately one year) until the $2^{\text {nd }}$ measurement time. After the $2^{\text {nd }}$ measurement, the standard LEDs were stored in a desiccator. The measured long-term stabilities of total luminous flux of the 10 standard LEDs are shown Figure 5. Except the standard LEDs L\#24 (yellow line and round dots) and L\#26 (green line and round dots), variation of an LED's total luminous flux is within $0.2 \%$ (that includes the long-term drift of the measurement system), and the variation of the average total luminous flux is within $0.1 \%$ (the thick black line and squared dots) over the three-year period, which is superior. Further, the one-year continuous operation for seasoning resulted in virtually no change in luminous flux, which agrees with the aging test result shown in Figure 4. Therefore, the slow, time-consuming seasoning process is not needed for this type of standard LEDs operated at $1 \mathrm{~A}$, and they may be used as standard LEDs from when they are brand new.

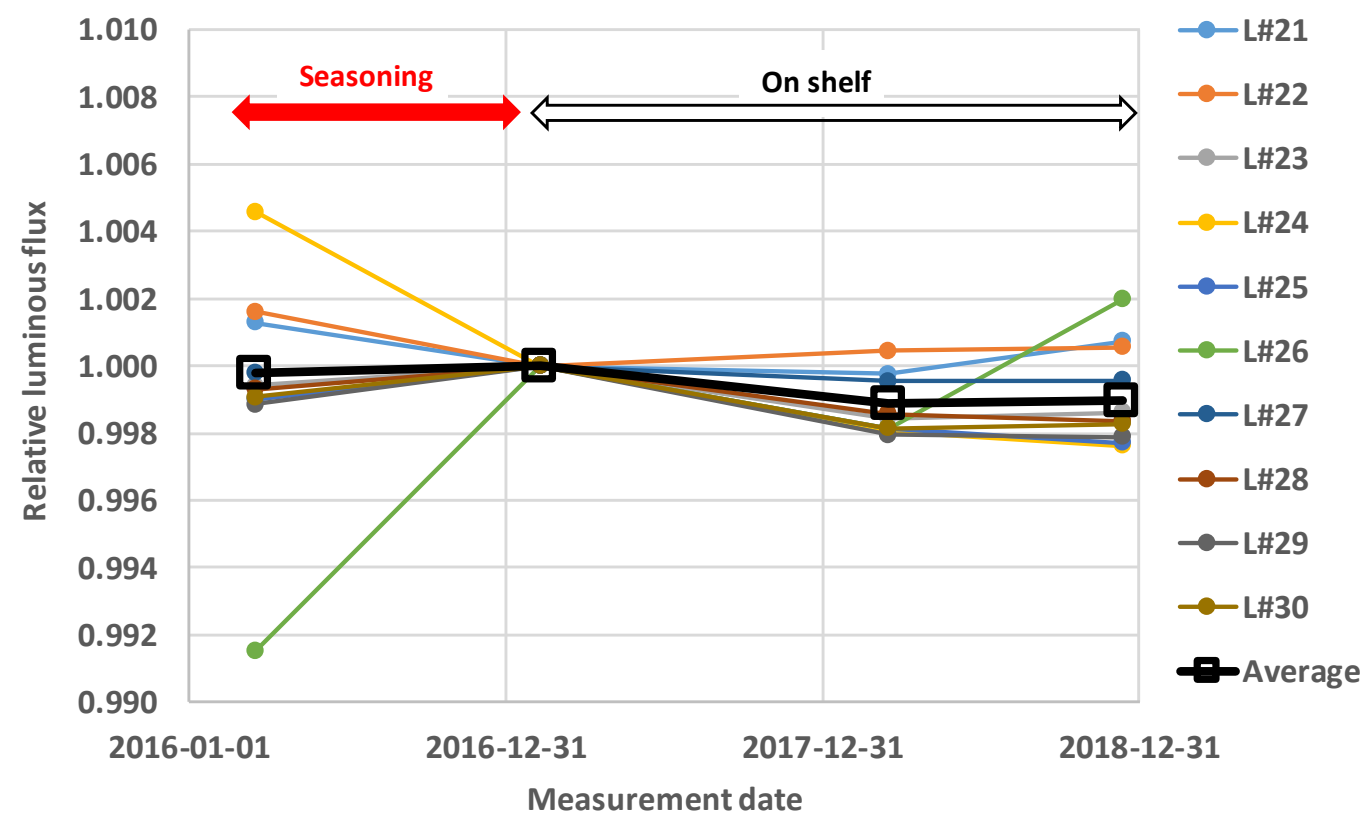

Figure 5 - Measurement result of long-term stability

\section{Summary}

We developed a large-chip ( $3 \mathrm{~mm} \times 3 \mathrm{~mm}$ square) standard LED with virtually no aging effect. The LED has superior on-shelf long-term stability (approximately $0.1 \%$ over three years) and can be used as a standard LED for luminous intensity, luminance, and total luminous flux.

\section{Acknowledgements}

The authors want to thank their colleagues Benjamin Tsai and Maria Nadal for their support on this research.

\section{Reference}

NIST 2018. NIST Special Publication 250-95. Yuqin Zong, Maria E. Nadal, Benjamin K. Tsai, and C. Cameron Miller. NIST Measurement Services - Photometric Calibrations. Gaithersburg: NIST.

https://www.nist.gov/publications/nist-measurement-services-photometric-calibrations 